gina; the uterus should at the same time be supported supra pubem. The best material for the tampon is iodoform gauze (10 to 20 per cent.), cut into strips; but, if this is not at hand, strips of sterilized cloth will do very well. Long uterine dressing forceps, or placenta forceps, will serve to apply the tampon and no speculum is necessary. Previous to the application of the tampon the uterus and vagina should be cleansed with a corrosive douche. The tampon should be firmly applied from fundus to cervix ; and, if there is bleeding from cervical or vaginal tears, the vagina should also be packed. The tampon should be left in situ only a few hours, in which time the uterus will have recovered its tonicity and contractions will have been excited by the presence of the tampon as a foreign body.

\section{Elinital g্Department.}

\section{TWO CASES OF SUSPECTED ANEURISM OF THE AORTA. 1}

BY F. I. KNIGHT, M.D.

IN the first of these cases the autopsy confirmed the diagnosis, and in the other failed to do so.

CAsE I. The patient was seen January 31,1889 , for the first time. He was thirty-nine years old; a freight-train conductor; was usually strong and well. His physician thinks he has had syphilis. In April, 1887, he experienced a violent strain of the left arm in moving a switch. There has been no pulse in left radial since that time. There is no record of any examination before this. For a year there was severe pain and weakness of the left arm. In August, 1888, was much exposed in bad weather, and took a severe cold, which resulted in a cough, which has since con. tinued. Has not been able to work much since. Has been "wheezy" since October 20, 1888. Exercise wakes breathing very hard. A little dysphagia since October 1, 1888. Sovere substernal pain, radiating to the left. Pulse 68, regular, in right radial ; cannot be felt in left. No dulness on percussion of chest. No murmurs over heart or vessels. The respiratory murmur was of equal intensity over both sides of the chest. There was a short, deep, coarse, expiratory sonorous râle heard over the sternum and near it on both sides. 'There was no difference in the pupils of the eyes. The movements of the vocal cords were normal.

The diagnosis was made aneurism of the aorta? of course with the interrogative. He was put upon the iodide of potassium in increasing doses, and perfect rest was ordered.

March 15, 1889, the following report was made by his family physician: "Mr. X. is better. I can now, for the first time in two and one-balf years, count his pulse in left wrist. I could feel the pulsation there for the first time about two weeks ago. The stridulous breathing is not as marked, though it is trouble. some yet. The dysphagia is much less. The sleep is disturbed by neuralgic pain, and there is some acne. He is now taking forty-five grains of the iodide of potassium three times a day, and is quiet in bed."

May 4, 1889, I saw the patient again. He said that he renuained in bed about six weeks from the time of

1 Reported at the meeting of tho Boston Sooloty for Modical Improvenient, November 24,1890 . his first visit to me, after that he kept quiet in the house till about ten days ago. He improved till he went out; since then the cough and dysphagia had been worse.

On examination I could feel slight pulsation in the left radial, and there was less sonorous râle in expiration near the sternum. Otherwise no change in the physical sigus.

He got restless, and went to work in July as conductor of a freight train; worked well till January.

February 24, 1890, his physician wrote me as follows: "Mr. X. went along well, taking forty grains of iodide of potassium three times a day, until the last of December, when he began to complain of great pain in left side of neck, and in region of the heart. 'There was a fulness of neck above clavicle on this side. I was sent for January 4,1890 , and fodnd him partially paralyzed on the right side, with loss of power to articulate. In a few days he recovered the use of his limbs, so that he could walk around the house. $\mathrm{He}$ could talk, though not very well, and often could not say the word he wanted. February $22 d$ he had a recurrence of the attack, but is a little better to-day."

The patient took no iodide after December, 1889 , but had taken forty to fifty grains, three times a day, from January 31,1889 , till that date, with an omission of a few days on account of gastric disturbance. He suffered severe pain under the left clavicle, extending up the side of the neck, which increased in severity during the latter months of his life. In March an attack of influenza aggravated all his symptoms, especially the difficulty in speaking.

The pain became so severe that early in June he was put upon opium in full doses, and he improved so that he rode about town in July and August without increase of pain; and one day rode eighteen miles without apparent ill result.

About June 10th a pulsating tumor appeared under the left clavicle, which constautly increased in size till his death.

August 25th he was riding, and stopped near home to witness a ball game, He hawked up a mouthful of blood; was driven home within three minutes, fainted as he was taken from the carriage, but recovered enough to vomit as soon as he was tuken into the house. He vomiter a large quantity of blood. He was in a state of collapse and pulseless, when the doctor arrived. During the night he rallied, so that in the morning he was warm, with a faint pulse and quite cheerful. 'Two days after he had a large dejection of coagulated blood from the bowels.

August 29th, four days after first hamorrhage, he vomited blood again freely, and died in about two hours.

His appetite and digestion were always good, and he maintuined his usual weight.

At the autopsy the stomach was found full of clotted blood. There was a large aneurism of the arch of the aorta, which showed a small secondary pouch just at the origin of the left subclavian artery. 'There was a large perforation of the cosophagus about an inch above the level of the bifurcation of the trachea, and also an ulceration very nearly through the trachea about the same distance from the bifurcation. The heart seemed rather large; there was no valvular disease.

The case was interesting in several respects. The mode of origin would naturally challenge one's atten- 
tion. Did syphilis act as a predisposing cause? It may have, though there was nothing post-mortem to suggest it. Did strain act as an exciting cause? The patient's symptoms certainly date from that accident. Did obliteration of the left radial pulse occur at the time of the accident? We cannot be sure about this, for he had not been examined previously to this.

Did the treatment have anything to do with the patient's temporary improvement? Rest certainly did. There was nothing in the appearance of the aneurismal sac to indicate that the iodide of potassium had any effect locally.

The cause of the improvement in the left radial pulse was probably due to the condition or position of the little pouch near the origin of the left subclavian. The improvement in the dysphagia was probably due to a diminution in tension of the large sac by rest. The head was not examined, but the right hemiplegia was undoubtedly embolic.

CAse II. The second patient was seen by me October 9,1890 . He was fifty-eight years of age, and had always been well previous to his present sickness. $\mathrm{He}$ had lost the right forearm by an accident a fow years before. His present sickness began with dyspnoea and cough last May. The dyspnoea had gradually increased, and there had been orthopnœa two months. 'There was a little dysphagia. Pulse 108, soft, quick, regular. Dulness over upper part of sternum, and in the first and second spaces to the left. There was marked pulsation in the second left intercostal space near the sternum. Bronchial respiration near the sternum at top of left lung, and at top of left shoulder. Elsewhere in left front the respiratory murmur was feeble. Systolic murmur over left chest, most marked in left interscapular region. Superficial veins of integument of lower part of chest distended. Feet and ankles coematous.

Complete rest was ordered, with the iodide of potassium. He gradually grew worse and died October 25 th.

At the autopsy a very large tumor was found, compressing the trachea, esophagus, hud apex of the left lung.

In this case the diagnosis of uneurism seemed more certain than in the previous one, inasmuch as one had in addition to the pressure signs also those of a marked pulsation in the second left intercostal space. But the one crucial test of an aneurism failed, that is, there was no expansion of the swelling under one's fingers, laterally as well as vertically. The tumor proved to be a malignant lymphoma.

\section{Reporti af Sacietieg.}

\section{BOSTON SOCIETY FOR MEDICAL OBSERVA- TION.}

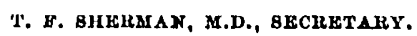

Rlgular Meeting, Monday, November 8, 1890.

Dr. Josepin Stedman read a paper on

cerebral tumors, with clinical cases. ${ }^{1}$

Dr. WebBer: I have been very much interested in the series of cases, and having seen two of them I was very much interested in hearing the others. The second case reported, which I saw, was a very interesting one, as showing so few of the symptoms of brain tumor. In that case there was, I think, nothing but headache as a general symptom preceding the last serious illness, and that headache disappearing and the patient being able to go out and take photographs. Headache is one of the most comrion symptoms in brain tumor, sometimes the most marked of all the symptoms, sometimes very excruciating, eclipsing and concealing all the other symptoms, the patient and his friends giving all their attention to the headache which is so severe. Others of the general earlier symptoms are dizziness, and inability to walk straight, lack of coordination, nausea and vomiting. Sometimes the very first symptom that attracts attention is a loss of mental power or a change of disposition, the person acquiring a certain amount of irritability ; if there is headache it is very likely to be ussigned as the cause of the irritability and the change of disposition. Frequently there is a geueral loss of motor power, a person becomes weak without any special paralysis, without any weakness of one side more than the other, yet there is a decided loss of power. Those general symptoms will frequently, the one or the other or all of them precede the localiziug symptoms; but here in the second case there was simply the headache. I think there was no change of disposition, no special staggering or dizziness and no nausea or vomiting, and 110 special motor weakness. Headache is not a good localizing symptom. 'The pain does not occur necessarily where the tumor is, but may be referred to other portions of the head. It depends upon how the pressure is exerted upon the nerves; it depends upon whether the pressure is exerted at the spot where the tumor is, or at a distant spot, whether a nerve is irritated which goes to some other region, so that the pain is referred to a part of the head distant from where the tumor is. When I saw this boy it was clearly a serious case. I was not called until the paralysis had occurred. 'That seemed to be caused by an attack of hamorrhage, as the autopsy proved. It was only by taking into account the previous headache and the previous symptoms that I could, I might say, guess there was a cerebral tumor. The rise of temperature and pulse toward the close of the disease was undoubtedly due to the hæmorrhage.

It is very common after a hamorrhage into the brain, in fact, it is the rule, to have rise of temperature. First, there is likely to be for a few hours a lowering of temperature, and then a steady rise, the temperature in very serious cases rising continuously, in cases that are less serious rising for a short time, then remaining stationary, and in favorable cases, where the hxmorrhage is not going to prove fatal, the temperature will go down again to normal; or if it is not going to terminate favorably, after the temperature has remained stationary for a short time it will rise again, so that undoubtedly the rise of temperature in this case was due to the homorrhage.

The case in which plugging of the artery occurred was a very instructive one to me, and interesting from the fact that previously, in 1882 , the patient had the symptoms which were mentioned; headache and a general feeling of discomfort, malaise, and weakness, being kept in the house for quite a while. At that time the possibility of a tumor was suggested, though I did not think that was it, and gave rather a favorable prognosis; I thought that he suffered from 